\title{
Evaluation of Shear Strength of Concrete Flat Plates Reinforced with GFRP Plates
}

\author{
Min Sook Kim and Young Hak Lee \\ Department of Architectural Engineering, Kyung Hee University, 1732 Deogyeong-daero, Yongin, Republic of Korea
}

Correspondence should be addressed to Young Hak Lee; leeyh@khu.ac.kr

Received 19 January 2017; Accepted 20 March 2017; Published 18 May 2017

Academic Editor: Sumin Kim

Copyright ( 2017 Min Sook Kim and Young Hak Lee. This is an open access article distributed under the Creative Commons Attribution License, which permits unrestricted use, distribution, and reproduction in any medium, provided the original work is properly cited.

\begin{abstract}
The shear performance of concrete flat plates with glass fiber-reinforced polymer (GFRP) plate shear reinforcement was investigated through punching shear tests. Each GFRP plate was embedded in the concrete and included openings to permit the flow of concrete during fabrication. Punching shear tests were conducted on a total of 8 specimens, and the resulting crack and fracture formations, strains, and load-displacement curves were analyzed and compared. The experimental variables considered were the types of shear reinforcement, including steel stirrups or GFRP plates, and the shear reinforcement spacing. The experimental results show that the GFRP shear reinforcement effectively increased the shear strengths of flat plates. Furthermore, the applicability of two formulas was investigated: a modified version of a shear strength formula from ACI 318-14 and the ACI 318-14 fracture prediction formula.
\end{abstract}

\section{Introduction}

The flat plate structure is composed of only slabs and columns, with no beams. Thus, brittle punching shear failure can occur owing to stress concentration near the column-slab joint. To prevent brittle failure arising from punching shear, the method of using fiber-reinforced polymer (FRP) material rather than a steel stirrup or stud rail as the reinforcement has been studied and applied. Esfahani et al. [1] attached a CFRP sheet to the slab exterior and conducted punching shear tests to evaluate the resulting shear performance. Faria et al. [2] applied FRP laminates to the flat slabs and proposed Critical Shear Crack Theory to estimate the shear strength of flat slabs reinforced with FRP laminates. Erdogan et al. [3] proposed CFRP dowel system. CFRP dowels are installed in the predrilled hole of the slabs to act as shear reinforcement. Sissakis and Sheikh [4] manufactured an annular CFRP and reinforced it by punching a hole in a slab to experimentally assess its performance and to evaluate the applicability of the CSA and ACI equations. There has been steady research based on methods of strengthening the slab with FRP sheet or FRP straps, whereas research into the use of substitute shear reinforcement is more limited [5]. In this paper, we propose a method of enhancing the shear performance by embedding perforated FRP plates in the flat plate. This performance was empirically verified in previous studies [6]. Figure 1 illustrates the shape of the perforated GFRP plate. The GFRP fiber direction was oriented so that the plates would follow the horizontal and vertical component directions of the plate. The openings in the GFRP plate permit the flow of the concrete, leading to the expectation of enhanced adhesion between the concrete and the FRP plate. GFRP plates were installed on each of the four sides surrounding the column (Figure 2). Each GFRP plate was installed by fitting it between the slab and the upper and lower rebars.

To support the application of perforated GFRP plates as shear reinforcement in concrete flat plates, shear tests were conducted using the design variables of shear reinforcement type and spacing. The crack and failure modes of each specimen, load-displacement behaviors, flexural reinforcement strains, and GFRP plate strains were evaluated. Based on the experimental results, a recommended maximum shear reinforcement spacing for the GFRP plates was determined. Moreover, a modified shear strength equation in the ACI 


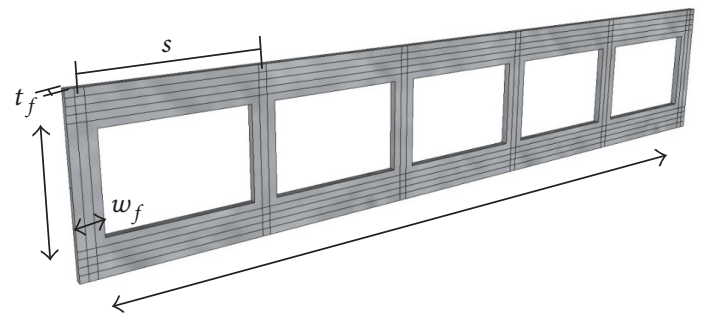

FIGURE 1: Shape of a GFRP plate.

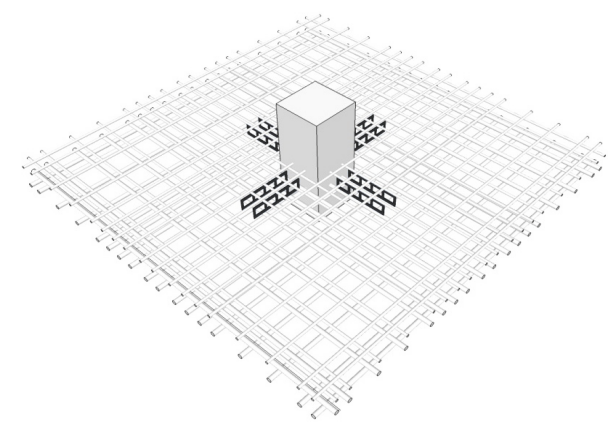

FIGURE 2: Schematic view of the proposed design for a flat plate reinforced with GFRP plates.

TABLE 1: Material properties.

\begin{tabular}{lccc}
\hline & $\begin{array}{c}\text { Diameter } \\
(\mathrm{mm})\end{array}$ & $\begin{array}{c}\text { Tensile strength } \\
(\mathrm{MPa})\end{array}$ & $\begin{array}{c}\text { Modulus of elasticity } \\
(\mathrm{GPa})\end{array}$ \\
\hline $\begin{array}{l}\text { Tension bar } \\
\text { Column bar }\end{array}$ & 22.2 & 500 & 200 \\
Stirrup & 9.5 & 400 & 200 \\
GFRP & - & 480 & 50 \\
\hline
\end{tabular}

318-14 [7] was evaluated, and the applicability of the fracture mode prediction equation provided in ACI 318-14 was verified.

\section{Experimental Program}

2.1. Materials. The design strength of the concrete used to fabricate specimens was $21 \mathrm{MPa}$. The average 28 -day compressive strength was measured to be $20.25 \mathrm{MPa}$. For the tension and column bars, deformed rebars of diameter $22 \mathrm{~mm}$ and yield strength $500 \mathrm{MPa}$ were used. For the column hoop bar and stirrup, deformed rebars of diameter $10 \mathrm{~mm}$ and yield strength $400 \mathrm{MPa}$ were used. GFRP with a tensile strength of $480 \mathrm{MPa}$ and Young's modulus of $50 \mathrm{GPa}$ was used for the shear reinforcement plates. Table 1 lists the properties of the materials used.

2.2. Specimen Details. A total of 8 specimens were manufactured: 5 specimens shear-reinforced with GFRP plates, 2 specimens reinforced with stirrups, and 1 specimen without reinforcement. Structural details of the specimens are shown in Figure 3. Each slab portion had horizontal dimensions of $2000 \mathrm{~mm} \times 2000 \mathrm{~mm}$, thickness of $180 \mathrm{~mm}$, and effective

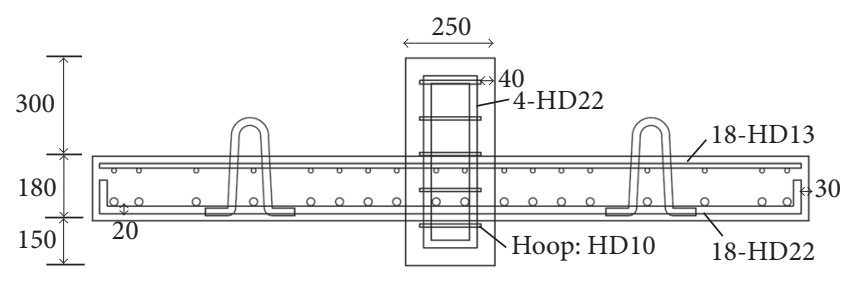

Figure 3: Cross-sectional view of the slab specimen.

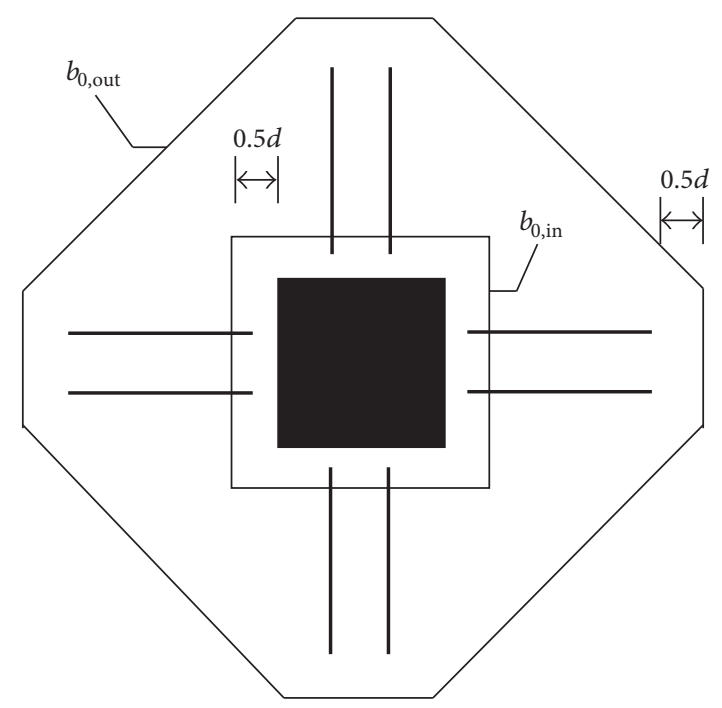

FIgUre 4: Critical sections according to ACI 318-14.

depth of $138 \mathrm{~mm}$. The columns had horizontal dimensions of $250 \mathrm{~mm} \times 250 \mathrm{~mm}$, upper column height of $300 \mathrm{~mm}$, and lower column height of $150 \mathrm{~mm}$. All specimens were designed to have the same flexural reinforcement ratio.

2.3. Specimen Design. Table 2 lists the details of each specimen. Specimens were named according to the experimental variables of shear reinforcement type, spacing, and amount. The control specimen was a specimen with no shear reinforcement. S and G refer to steel stirrups and GFRP plates, respectively, while $A, B, C$, and $D$ refer to the shear reinforcement spacings of 40,69,104, and $138 \mathrm{~mm}$. The shear strengths of the specimens were calculated using a modified ACI 318-14 equation. Figure 4 shows schematic diagrams of the internal critical section $\left(b_{0, \text { in }}\right)$ and the external critical section $\left(b_{0, \text { out }}\right)$. The internal critical section is located at a distance $0.5 d$ from the face of the column, and the external critical section is the octagonal region defined by points $0.5 d$ from the outermost part of the shear reinforcement. For the flat plate reinforced with shear reinforcement, the external critical section was determined using the design equation. As expressed in (1), the shear strength is the sum of the contributions to the shear strength by the concrete and the shear reinforcement. The concrete contribution to the shear strength was determined by calculating the compressive strength of the concrete according to (2), in accordance with the ACI 318-14. Equation (3) expresses the contribution of the GFRP plate to the shear strength. As reported in previous studies [6], the horizontal 


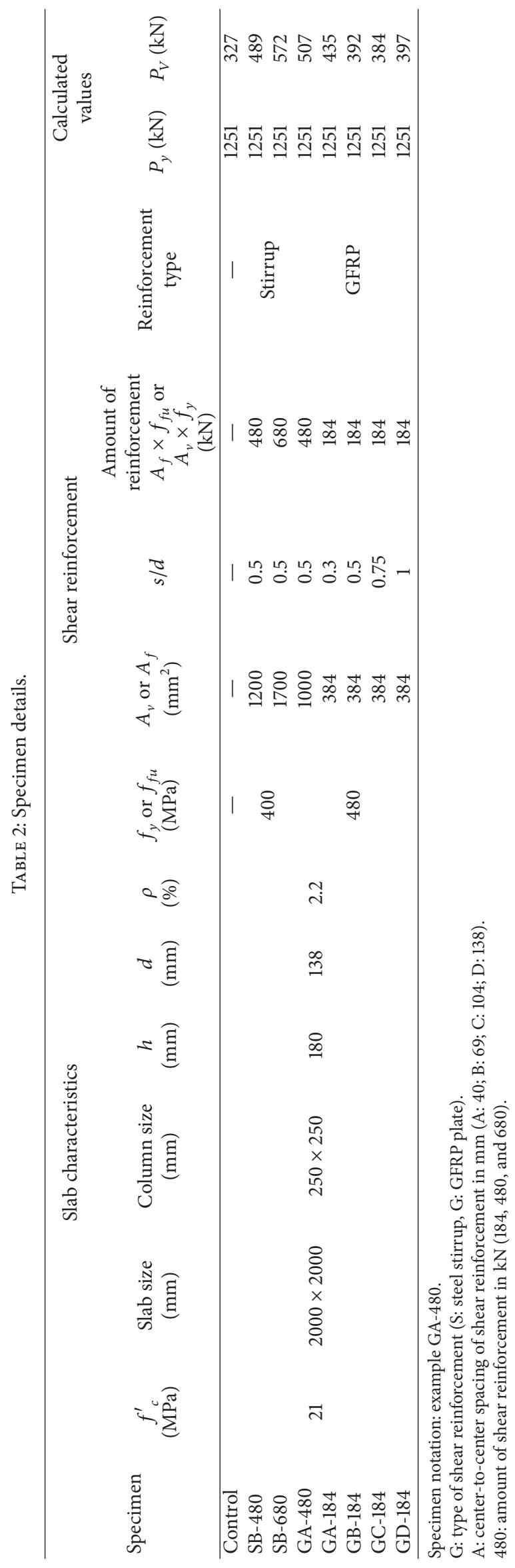


component of the GFRP plate does not significantly impact the shear force bearing performance. Thus, only the crosssectional area of the vertical component was considered in this calculation. Unlike the vertical components of the steel stirrups, those of the GFRP plate were of strip form; to take this shape into account, the shear reinforcement area of the plate was calculated using (4). The contribution of the GFRP plate to the shear strength was calculated as the number of GFRP plate vertical components according to (5) and by substituting this into (3). Hence,

$$
\begin{aligned}
V_{n} & =V_{c}+V_{f}, \\
V_{c} & =\frac{1}{6} \sqrt{f^{\prime}{ }_{c}} b_{0, \mathrm{out}} d, \\
V_{f} & =n A_{f} f_{f u}, \\
A_{f} & =8 t_{f} w_{f}, \\
n & =\frac{d}{s} .
\end{aligned}
$$

To assess shear performance, experiments were designed to induce a punching shear failure before bending failure. Here, the bending performance of the specimen was determined using the yield line theory of Johansen [8]. Johansen proposed that the magnitude of the maximum bending strength $P_{y}$ arising from the plastic flexural moment strength of a 4 -side simply supported slab can be calculated using (6). Hence,

$$
\begin{aligned}
& P_{y}=8 m_{r}\left(\frac{1}{1-c / l}\right), \\
& m_{r}=\rho f_{y} d^{2}\left(1-0.59 \frac{\rho f_{y}}{f_{c}^{\prime}}\right) .
\end{aligned}
$$

To calculate the shear strength, the shear reinforcement amount $\left(A_{f} \times f_{f u}\right.$ or $\left.A_{v} \times f_{y}\right)$ is represented by the product of the tensile strength and the shear reinforcement crosssectional area existing within the critical section. The SB-480 and GA-480 specimens had the same shear reinforcement amount, whereas the SB-680 specimen had a greater shear reinforcement amount than either of these. The shear reinforcement amounts of the GA-184, GB-184, GC-184, and GD184 specimens reinforced with GFRP plates were designed to be the same: $184 \mathrm{kN}$. The effect of shear reinforcement spacing on the shear strength was analyzed by varying the shear reinforcement spacing. The shear reinforcement installation locations within each specimen are shown in Figure 5.

2.4. Test Setup. To conduct testing of the specimen on a reaction frame, the 4 sides were simply supported using hinges specially fabricated for the experiment. Load was applied to each specimen using an actuator with maximum capacity of $1000 \mathrm{kN}$. In real structures, loading is applied to the slab, causing deflection and punching shears. However, in this experiment, the testing method was adopted of installing the flexural reinforcement on the lower part and applying the load to the upper column. On the lower side of the specimen, 5 displacement sensors (LVDTs) were installed to measure the vertical displacement. To determine the behavior of the flexural reinforcement, strain gauges were attached at constant intervals in the vertical and horizontal directions each from the column. Figure 6 shows the strain gauge installation points on the GFRP plate of the GC-184 specimen. The experimental setup is shown in Figure 7.

\section{Test Results}

3.1. Cracking and Failure Mode. Figure 8 shows crack patterns of the specimens' lower parts, whereas Figure 9 shows a cross section of $100 \mathrm{~mm}$ from the specimen column face, prepared using a concrete cutter. In the control specimen (i.e., the nonreinforced specimen), cracking began at the joint section between the column face and the slab, showing a typical punching shear failure in which the cracking led to a cone breakout up to the critical section. However, in the GFRP-reinforced specimens, after initial flexural crack formation, cracking continued to propagate diagonally from the column corner. Then, the shear crack gradually expanded in a radial form, increasing the crack width of the critical section. After the maximum load was reached, shear cracking was created in the direction toward the supporting point. The final crack formed in the lower part of the shear reinforced specimen was found to represent a wider failure area than that of the control specimen. These results show that the shear reinforcement provided a reinforcement effect, increasing the flat plate critical section $\left(b_{0}\right)$ so that more concrete resisted the punching shear. In the cross-sectional photographs shown in Figure 9, the failure surfaces of the upper and lower parts of each slab specimen are connected with dashed lines. In the control specimen, fracture began at the column face and formed a cone with a steep slope. Among all specimens studied, the GA-480 specimen showed a punching shear failure mode having the shallowest slope of cone failure. This reveals that the GA-480 specimen showed a greater reinforcement effect compared to that of the specimen with steel stirrup reinforcement.

3.2. Strain Distribution. Strain was measured for each specimen on the flexural reinforcement at points $150,250,350,550$, 700 , and $900 \mathrm{~mm}$ from the column face in the vertical and horizontal directions. The flexural reinforcement strains for each specimen at maximum loading are shown in Figure 10; the upper left corner of this figure includes a schematic illustration of the strain gauge installation locations. To allow comparison of the flexural reinforcement strains in the vertical and horizontal directions, strains measured from the horizontal flexural reinforcement are shown on the left side of the figure, while strains measured from the vertical flexural reinforcement are shown on the right. As can be seen in the figure, under maximum loading, all flexural reinforcement strains were below the yield strain value. Thus, it can be concluded that all specimens experienced punching shear failure before flexural beam yielding and flexural failure. Additionally, the control specimen showed the lowest strain among all specimens owing to the brittle punching shear 


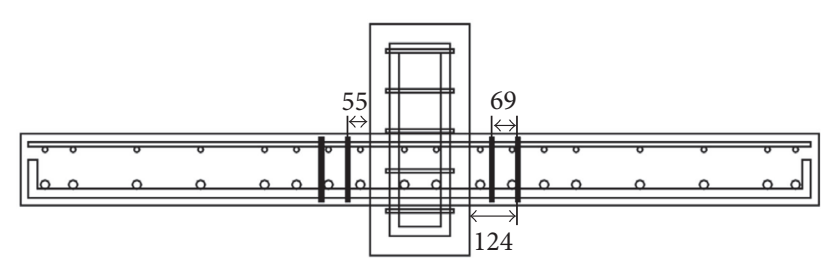

(a) SB-480

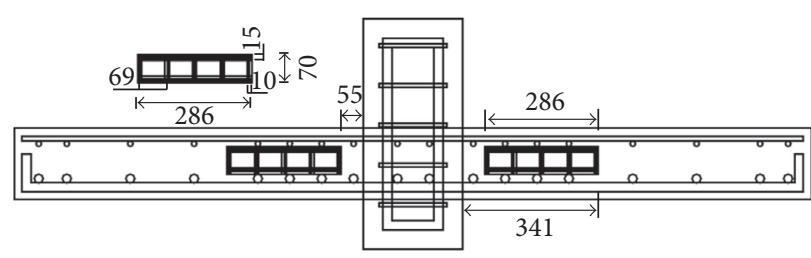

(c) GA-480

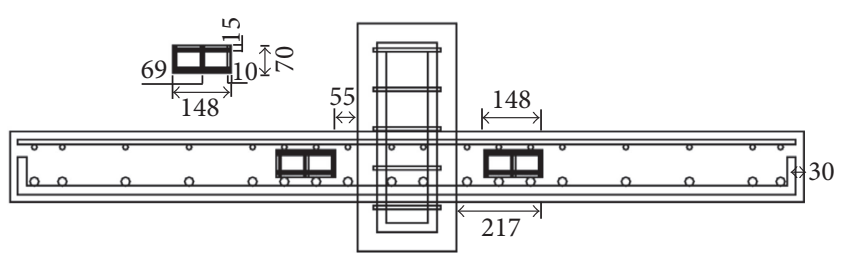

(e) GB-184

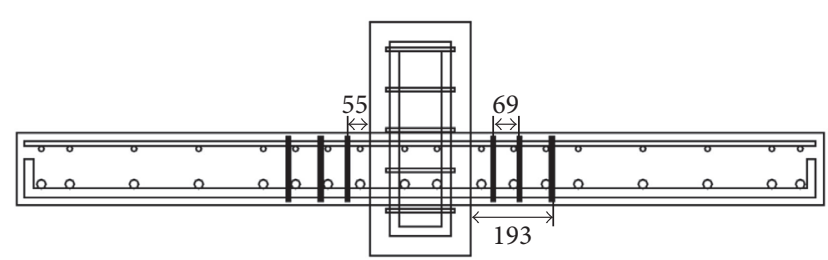

(b) SB-680

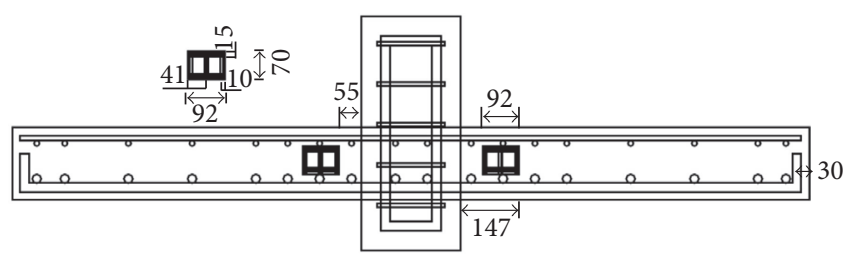

(d) GA-184

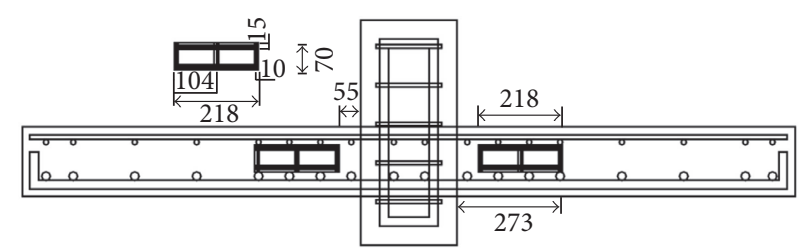

(f) GC-184

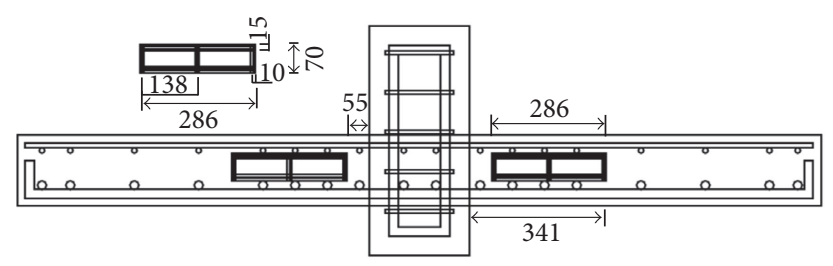

(g) GD-184

FIgURE 5: Arrangement of shear reinforcement in the specimen (dimensions in $\mathrm{mm}$ ).

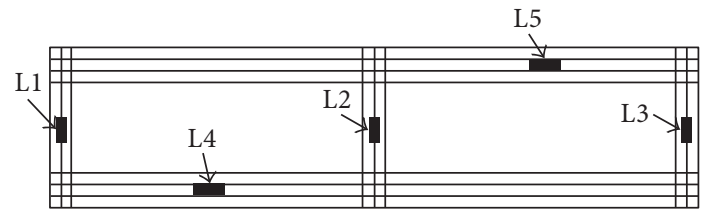

FIGURE 6: Strain gauge locations on the GFRP plate in the GC-184 specimen.

failure, and all specimens showed their greatest strains near the column.

Figure 11 shows load-strain curves of the GFRP plate in specimen GC-184. The L1 gauge strain of specimen GC184 recorded a small strain of $250 \mu \varepsilon$ before the initial crack formation at approximately $260 \mathrm{kN}$. However, the strain significantly increased during the beginning of shear crack, eventually leading to specimen failure at strains above $9000 \mu \varepsilon$. Large strains were measured for the vertical components L1, L2, and L3, showing that these effectively bore the punching shear and contributed to the observed shear performance. However, the horizontal component gauges L4 and L5 showed no significant changes in strain, even when the cracks propagated under the increasing applied loads.

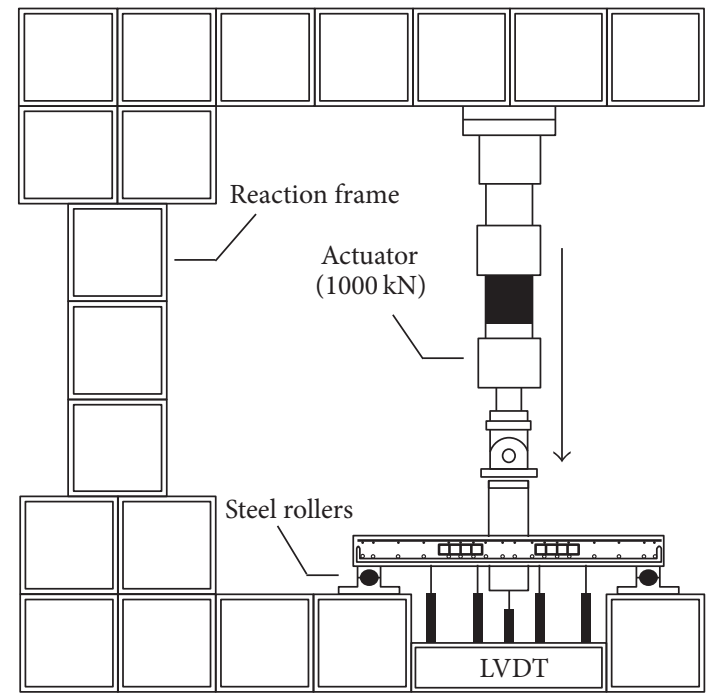

FIGURE 7: Experimental setup.

Therefore, it was concluded that the horizontal components of the GFRP did not substantially contribute to the punching shear performance of the flat plate. 


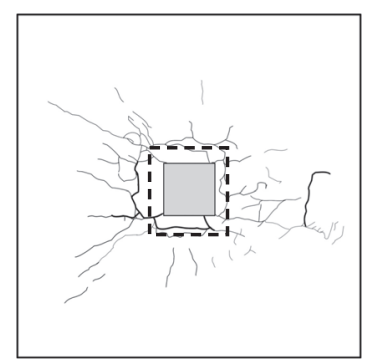

(a) Control

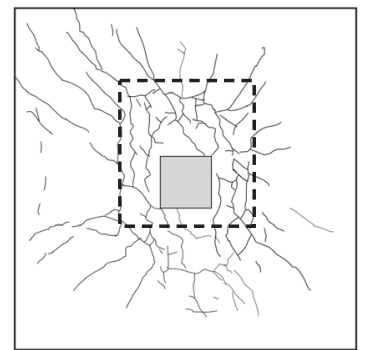

(e) GA-184

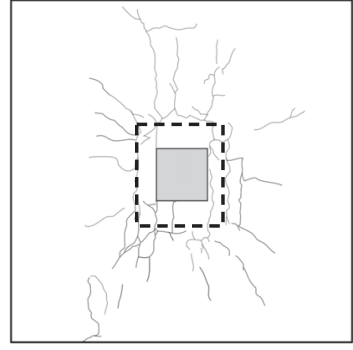

(b) SB-480

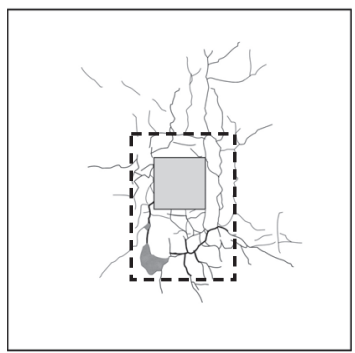

(f) GB-184

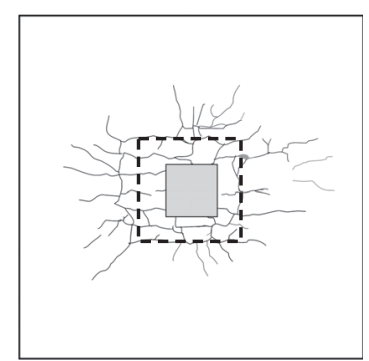

(c) SB-680

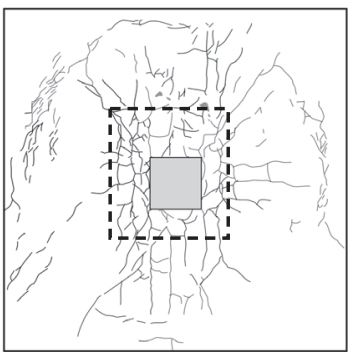

(g) GC-184

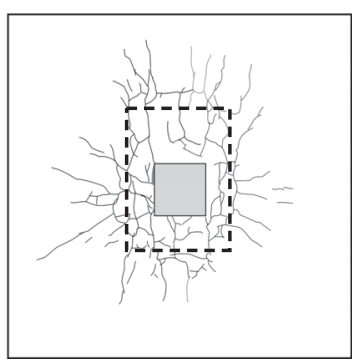

(d) GA-480

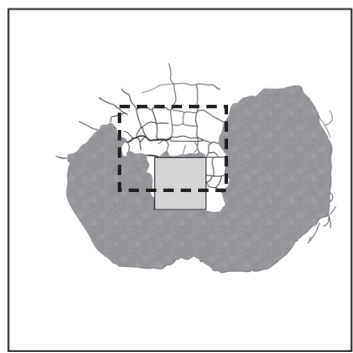

(h) GD-184

FIGURE 8: Crack patterns on the slab tension side of each specimen.

3.3. Type of Shear Reinforcement. The effect of the type of shear reinforcement was analyzed based upon the specimen load-displacement results. The maximum defection of the specimen was the displacement measured at the center of the column's lower part in the direction of gravity. Figure 12 shows load-displacement curves for specimens with various shear reinforcement types. The maximum loads for the control specimen, SB-480, SB-680, and GA-480 were 406, 637,780 , and $879 \mathrm{kN}$, respectively; the SB-480, SB-680, and GA-480 specimens showed shear performances 57\%, 92\%, and $116 \%$ greater than that of the control specimen. Also, although the SB- 480 specimen was designed to have the same amount of shear reinforcement as the GA-480 specimen, GA- 480 showed a $38 \%$ greater maximum load than that of SB-480. The SB-680 specimen was designed to have a shear reinforcement amount $40 \%$ greater than that of the GA-480 specimen, but GA-480 showed a maximum load $13 \%$ greater than that of SB-680. All steel stirrup-reinforced specimens showed maximum loads lower than that of the GA-480 specimen. The reason for this is that steel stirrups cannot effectively contribute to shear resistance owing to the difficulty in ensuring sufficient concrete cover thickness and effective depth. However, in the case of the GFRP plates, because each plate is installed between the upper and lower beams of the slab, this problem can be resolved. Thus, the GFRP plate shear reinforcement was determined to be more effective than the steel stirrups in resisting punching shear.

3.4. Spacing of GFRP Vertical Strips. The ACI 318-14 standard specifies the spacing limits of stirrup shear reinforcement of half the effective depth $(0.5 d)$. Whether the GFRP plate studied herein satisfies the ACI 318-14 standard as a steel stirrup replacement material was investigated through comparison testing. To carry this out, the shear reinforcement amounts of the GA-184, GB-184, GC-184, and GD-184 specimens were designed to be the same, at $184 \mathrm{kN}$, and their vertical component shear reinforcement spacings were designed to be $0.3 d, 0.5 d, 0.75 d$, and $d$, respectively. Comparison of the maximum shear strengths among the specimens with different shear reinforcement spacings showed that because the amounts of shear reinforcement resisting the actual punching shear were the same, the shear strengths were similar, at around $620 \mathrm{kN}$, for all specimens except GD184 (Figure 13). The shear strength of GD-184 was found to be $383 \mathrm{kN}, 94 \%$ of the $406 \mathrm{kN}$ shear strength of the control specimen. Because the GD-184 specimen had vertical component shear reinforcement spacing equal to the effective depth $(d)$ value of $138 \mathrm{~mm}$, it was determined that the shear reinforcement material in this specimen did not fully play its role. Contrastingly, the other specimens including GFRP plates as the shear reinforcement material exhibited sufficient resistance to the punching shear of the slab. Hence, applying the steel stirrup shear reinforcement spacing limit of the ACI 318-14 to GFRP plate material is not appropriate; instead, for GFRP plates, we recommend increasing the vertical component reinforcement spacing limit to $0.75 d$.

\section{Comparison between Experimental Results and ACI 318-14}

4.1. Shear Strength Equation for GFRP Reinforcement. We analyzed the applicability of the modified shear strength equation for the steel stirrup-reinforced flat plate presented in the ACI 318-14 standard for calculating the shear strength in the alternate case of a flat plate reinforced with embedded perforated GFRP plates. Table 3 and Figure 14 compare the 

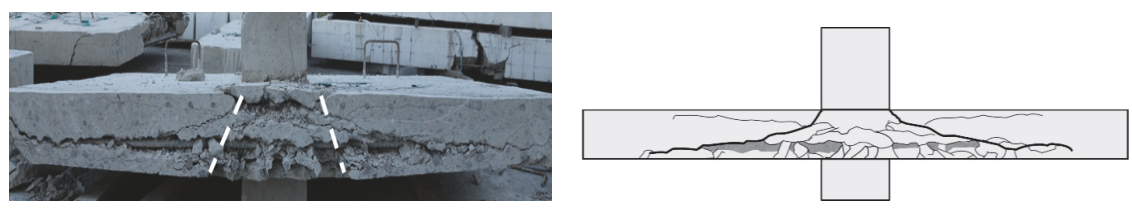

(a) Control
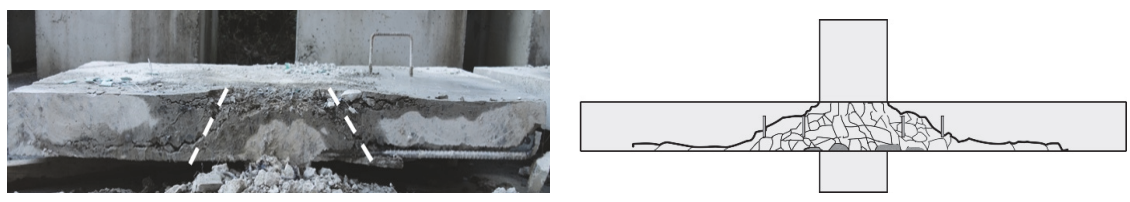

(b) SB-480
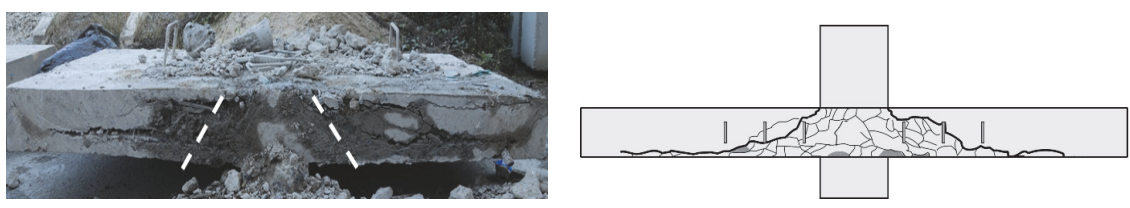

(c) SB-680
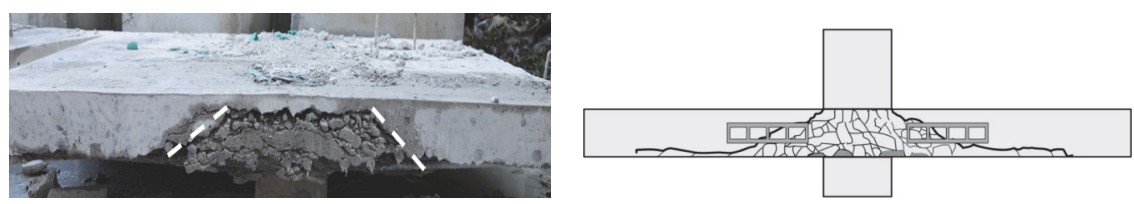

(d) GA-480
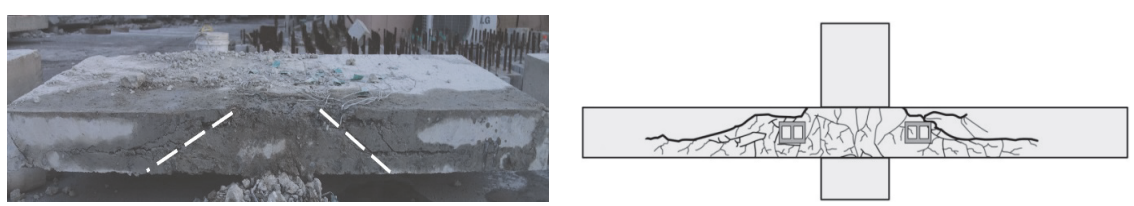

(e) GA-184
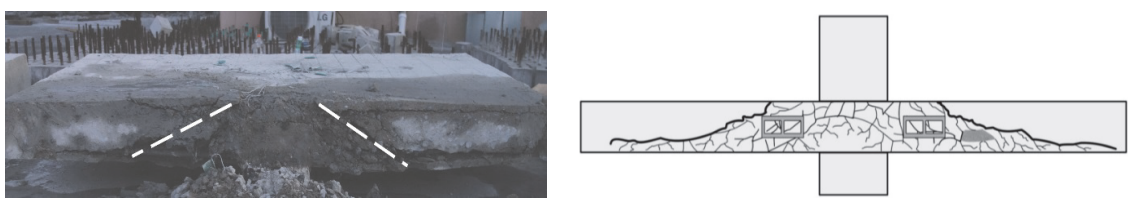

(f) GB-184
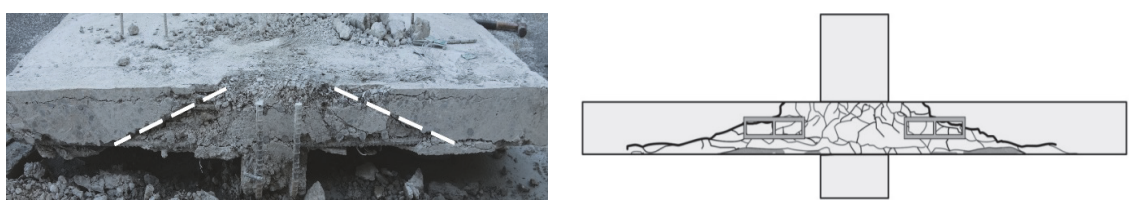

(g) GC-184
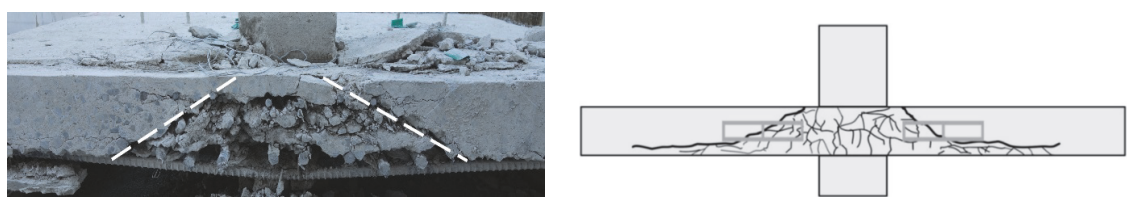

(h) GD-184

FIGURE 9: Cracking patterns in the saw-cut slab cross sections of each specimen. 
TABLE 3: Test results.

\begin{tabular}{lcccc}
\hline Specimen & Displacement $(\mathrm{mm})$ & $V_{\text {cal }}(\mathrm{kN})$ & $V_{\exp }(\mathrm{kN})$ & 406 \\
Control & 8 & 327 & 637 & $V_{\text {exp }} / V_{\text {cal }}$ \\
SB-480 & 12.23 & 489 & 780 & 1.24 \\
SB-680 & 15.48 & 572 & Average & 1.30 \\
& & & Standard deviation & 0.04 \\
\hline GA-480 & 16.66 & & 879 & 1.36 \\
GA-184 & 11 & 507 & 657 & 1.73 \\
GB-184 & 11.89 & 435 & 621 & 1.58 \\
GC-184 & 10.35 & 392 & 612 & 383 \\
GD-184 & 6.8 & 384 & 397 & 0.96 \\
\hline
\end{tabular}

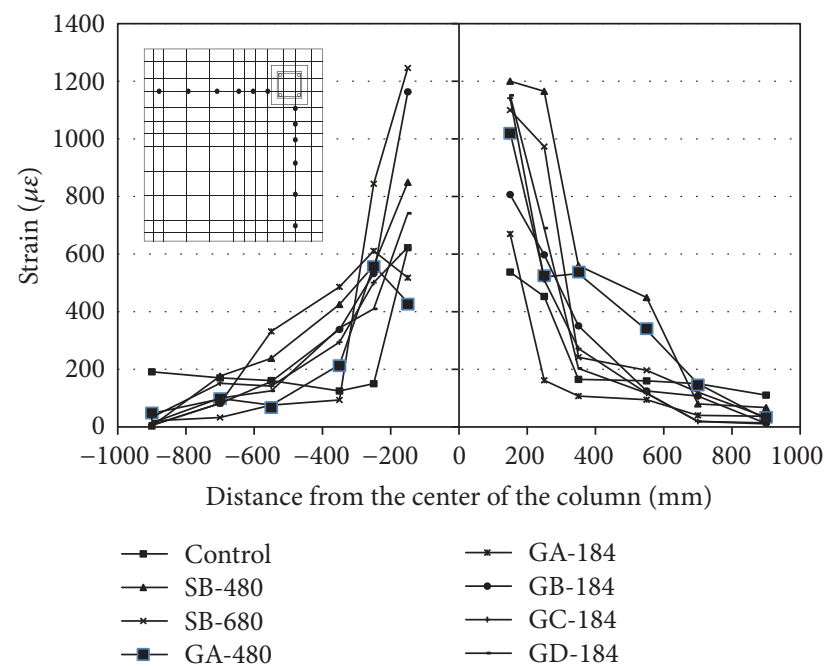

FIgURE 10: Strains in bottom reinforcing bars at peak load.

shear strength calculated using the modified ACI 318-14 shear strength equation and that measured experimentally. The ratios of calculated to measured shear strengths were found to be on average 1.3 , with a standard deviation of 0.04 , for the steel stirrup-reinforced specimens and the nonreinforced specimen, representing reasonable accuracy of the ACI 31814 equation for predicting the experimental shear strength. However, for the GFRP-reinforced specimens, the ratios of calculated to measured shear strengths were found to be on average 1.47 , with a standard deviation of 0.26 . Thus, the modified ACI 318-14 equation more highly underestimated the shear performance of the GFRP plate than that of the nonreinforced or steel stirrup-reinforced specimen.

The failure modes of a shear reinforced flat plate can be largely categorized into failures beginning from the inside of the shear reinforcement and those beginning from the outside. Analysis was conducted to verify whether the failure mode prediction equation, which is a modification of the steel stirrup equation for the GFRP plate, was suitable. Equations (8) and (9) are used to calculate shear strength for failure starting inside the GFRP plate. Here, the contribution of

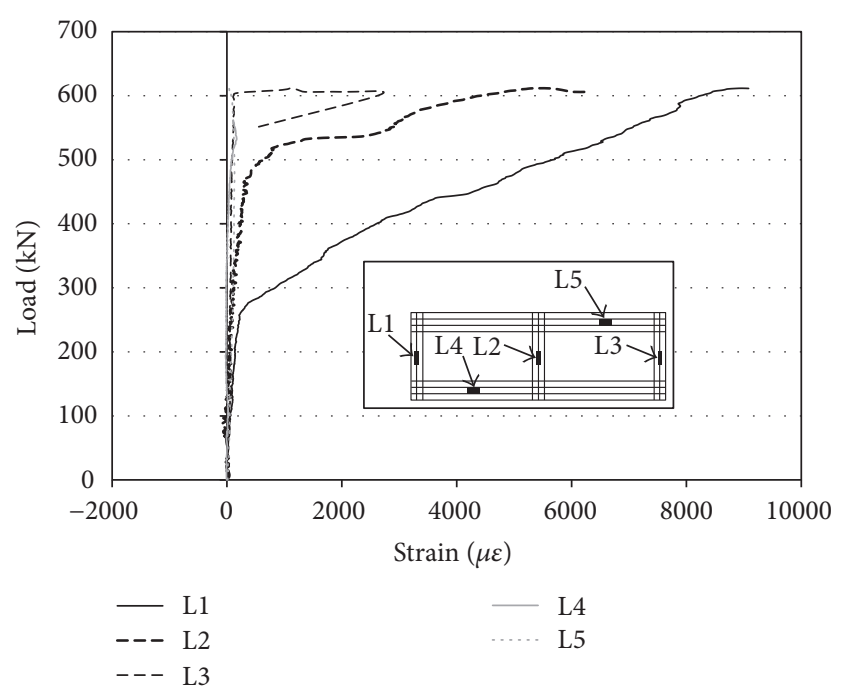

FIgURE 11: Load versus GFRP strain for the GC-184 specimen.

the critical section of concrete is set using the internal critical section $\left(b_{0, \text { in }}\right)$, that is, the portions up to $0.5 d$ vertical and horizontal distances from the column (recall Figure 4). Hence,

$$
\begin{aligned}
& V_{n, \text { in }}=V_{c, \text { in }}+V_{f}, \\
& V_{c, \text { in }}=\frac{1}{6} \sqrt{f^{\prime}{ }_{c}} b_{0, \text { in }} d .
\end{aligned}
$$

The shear strength equation for failure beginning outside the GFRP plate is shown in (10). The external critical section $\left(b_{0, \text { out }}\right) 0.5 d$ from the shear reinforcement domain was considered to be the critical section, and the shear strength contribution of the shear reinforcement was not included. Therefore,

$$
V_{n, \text { out }}=\frac{1}{6} \sqrt{f^{\prime}} b_{0, \text { out }} d
$$

The flat plate failure mode can be predicted by comparing the values of $V_{n \text {,in }}$ in (8) and $V_{n \text {,out }}$ in (10). Table 4 lists 
TABLE 4: Failure modes.

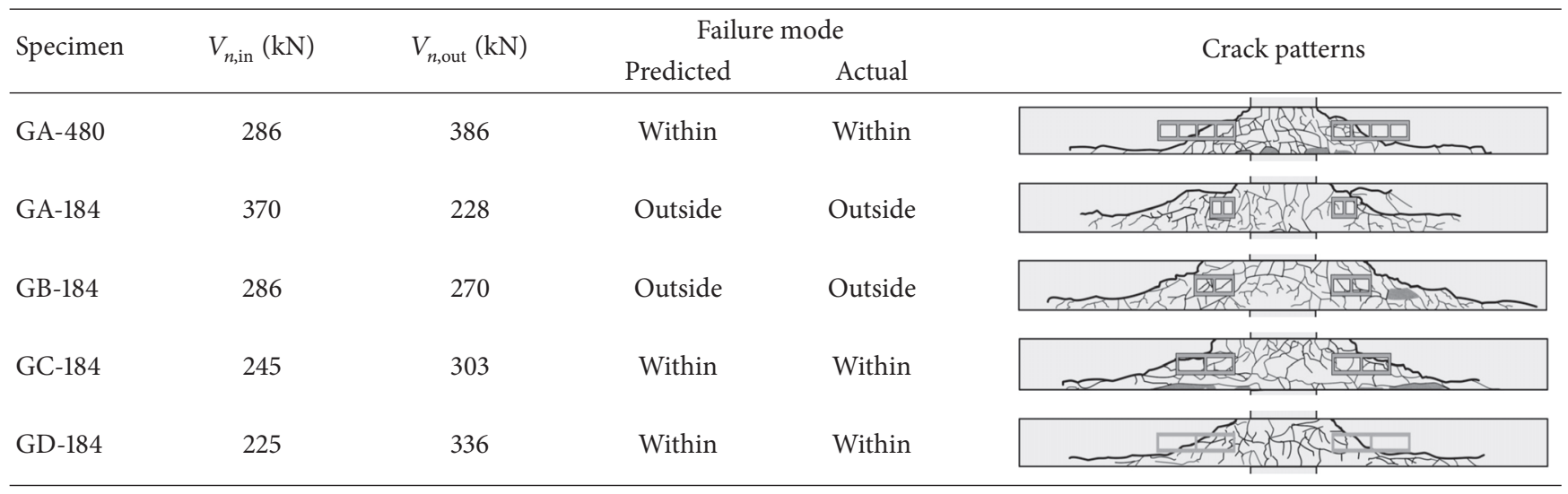

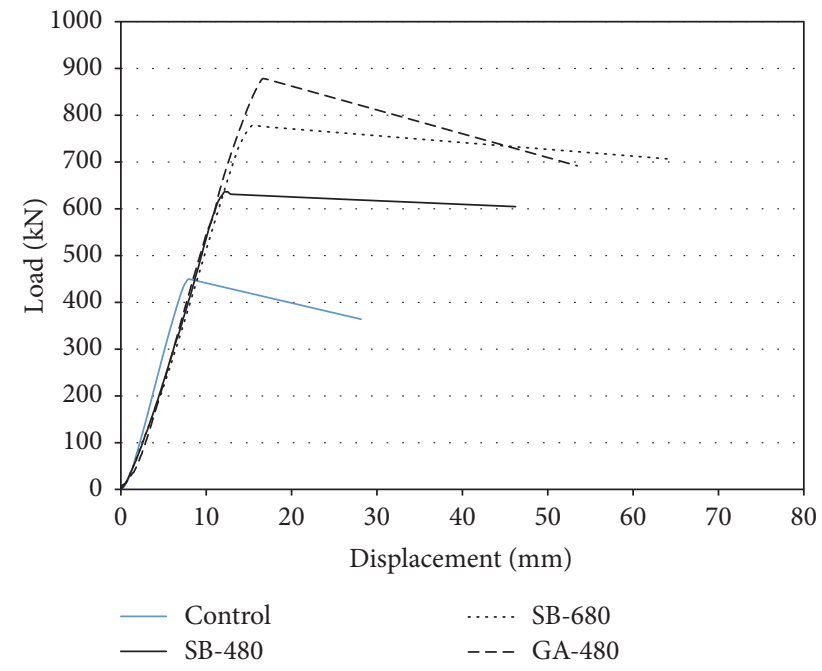

FIGURE 12: Load-displacement curves.

the predicted and actual failure modes; the predicted failure modes were correct for all specimens. Therefore, it was concluded that the failure mode prediction equation was accurate for a flat plate reinforced with GFRP plates.

\section{Conclusions}

In this paper, the shear performance of a flat plate including GFRP plates was evaluated as a shear reinforcement material. Punching shear tests were conducted in which the fracture and failure modes, strains, and load-displacement curves of 8 flat plate specimens were compared. The conclusions obtained from this study are as follows:

(1) Among the failed specimens, those including GFRP plates experienced cone failures with more gradual slopes and greater critical sectional areas compared to those of the steel stirrup-reinforced and nonreinforced specimens. Therefore, the GFRP plates were effective as reinforcement against the punching shear.

(2) Comparison of load-displacement curves of the specimens including GFRP plate reinforcement showed

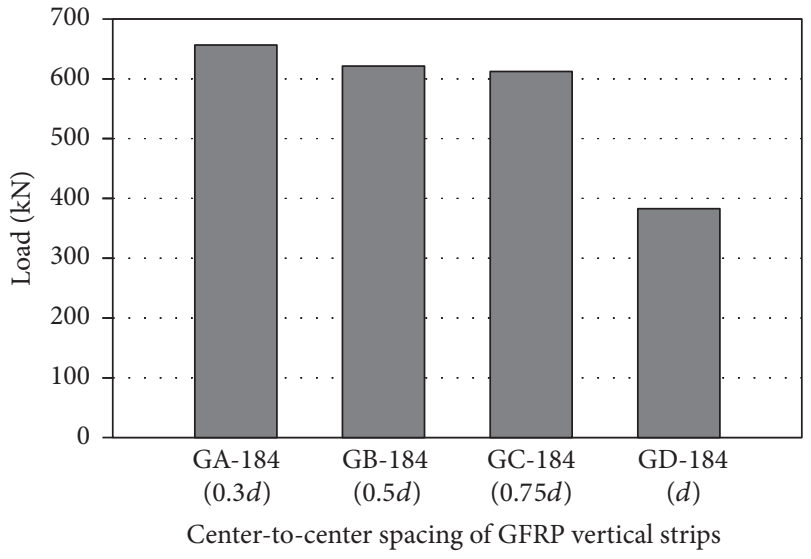

FIGURE 13: Shear strength depending on the spacing of GFRP vertical strips.

that, with increasing applied loads, the strains of the vertical components increased greatly, causing failure of the GFRP plate at strains greater than $9000 \mu \varepsilon$, whereas the horizontal components did not experience significant changes in strain over the range of loads applied. Thus, the GFRP plate vertical component contributes substantially to the punching shear performance of the slab. Considering only the vertical component of the GFRP plate as the shear reinforcement when calculating the shear strength of the shear reinforcement sectional area was found to be effective.

(3) The specimen including GFRP plates with the vertical component reinforcement spacing of $1 d$ did not fully exhibit its shear performance, but specimens of reinforcement spacing $0.75 d$ showed sufficient shear performance. Therefore, it is recommended that the maximum limit of shear reinforcement spacing be increased to $0.75 d$ for GFRP plates.

(4) A GFRP plate shear strength equation modified from the ACI 318-14-11 standard equation was validated by comparing its results to experimental shear strength results. For GFRP-reinforced specimens, the ratios of 


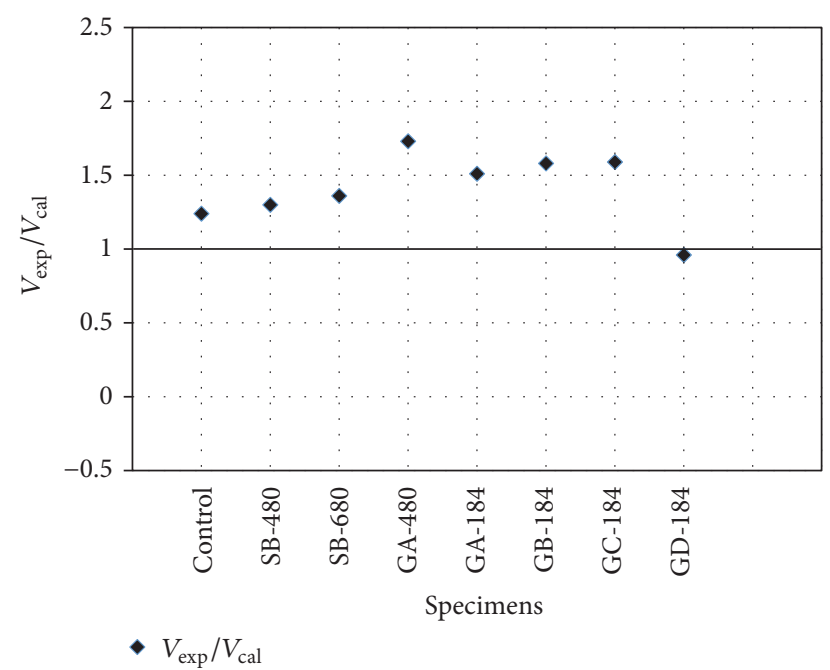

FIGURE 14: Comparison of experimental and calculated shear strengths.

experimental to calculated shear strengths $\left(V_{\text {exp }} / V_{\text {cal }}\right)$ were found to be on average 1.47 , with a standard deviation of 0.26 . Thus, the equation was determined to be applicable as a shear strength equation in the case of a flat plate reinforced with GFRP plates. Furthermore, the failure mode prediction equation provided in ACI 318-14-11 was found to accurately predict the failure modes of all GFRP-reinforced specimens.

\section{Conflicts of Interest}

The authors declare that they have no conflicts of interest.

\section{Acknowledgments}

This work was supported by the National Research Foundation of Korea (NRF) grant funded by the Korean Government (MSIP) (NRF-2017R1A2B2005581).

\section{References}

[1] M. R. Esfahani, M. R. Kianoush, and A. R. Moradi, "Punching shear strength of interior slab-column connections strengthened with carbon fiber reinforced polymer sheets," Engineering Structures, vol. 31, no. 7, pp. 1535-1542, 2009.

[2] D. M. V. Faria, J. Einpaul, A. M. P. Ramos, M. F. Ruiz, and A. Muttoni, "On the efficiency of flat slabs strengthening against punching using externally bonded fibre reinforced polymers," Construction and Building Materials, vol. 73, pp. 366-377, 2014.

[3] H. Erdogan, B. Binici, and G. Ozcebe, "Effect of column rectangularity on CFRP-strengthened RC flat plates," Magazine of Concrete Research, vol. 63, no. 7, pp. 511-525, 2011.

[4] K. Sissakis and S. A. Sheikh, "Strengthening concrete slabs for punching shear with carbon fiber-reinforced polymer laminates," ACI Structural Journal, vol. 104, no. 1, pp. 49-59, 2007.

[5] M. Hassan, E. A. Ahmed, and B. Benmokrane, "Punching shear behavior of two-way slabs reinforced with FRP shear reinforcement," Journal of Composites for Construction, vol. 19, no. 1, Article ID 04014030, 2015.

[6] D.-J. Kim, M. S. Kim, J. Choi, H. Kim, A. Scanlon, and Y. H. Lee, "Concrete beams with fiber-reinforced polymer shear reinforcement," ACI Structural Journal, vol. 111, no. 4, pp. $903-$ 912, 2014.

[7] ACI Committee 318, Building Code Requirements for Reinforced Concrete and Commentary (ACI318-14), American Concrete Institute, Farmington Hills, Mich, USA, 2014.

[8] K. W. Johansen, Yield-Line Formulae for Slabs, Cement and Concrete Association, London, UK, 1998. 

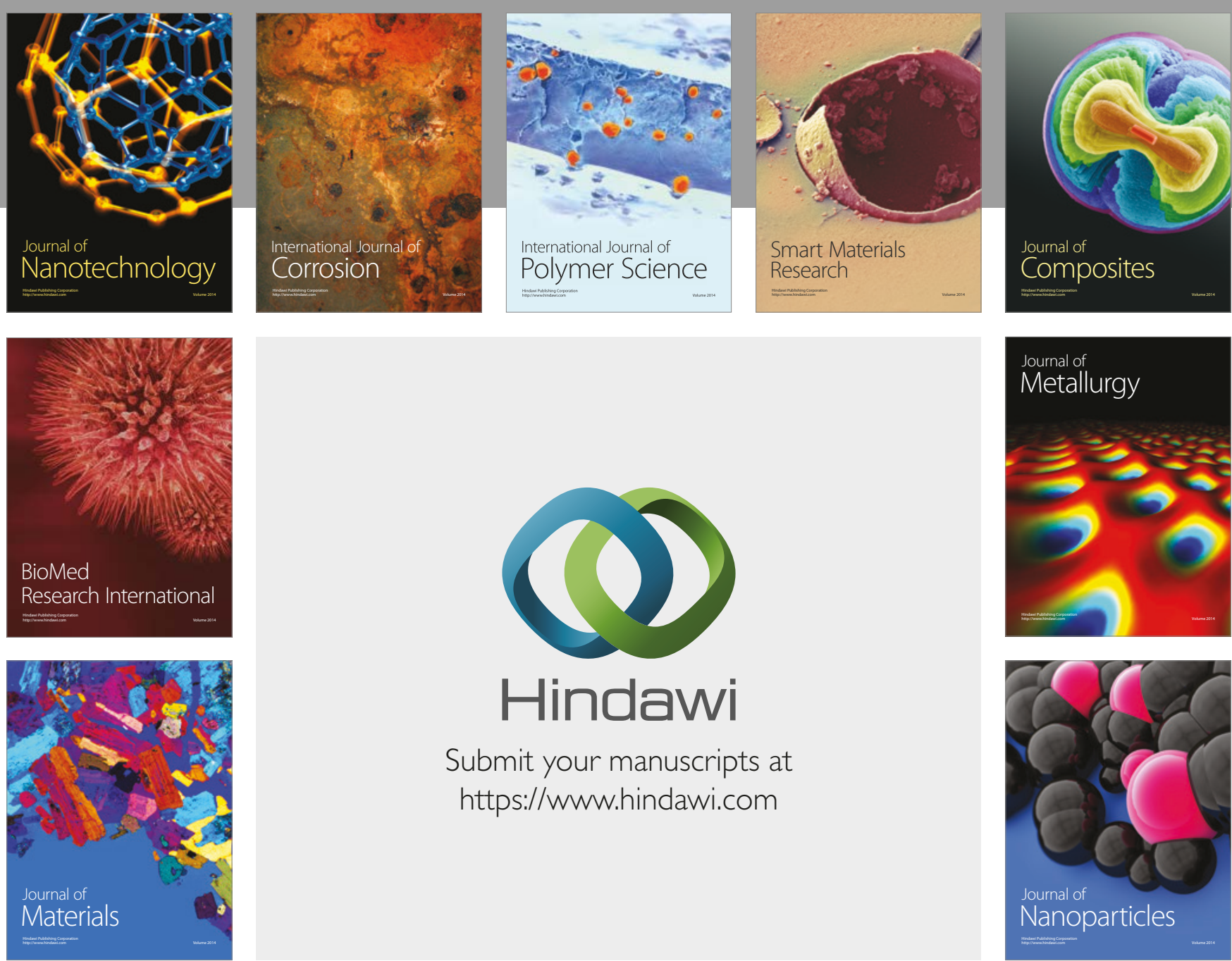

\section{Hindawi}

Submit your manuscripts at

https://www.hindawi.com
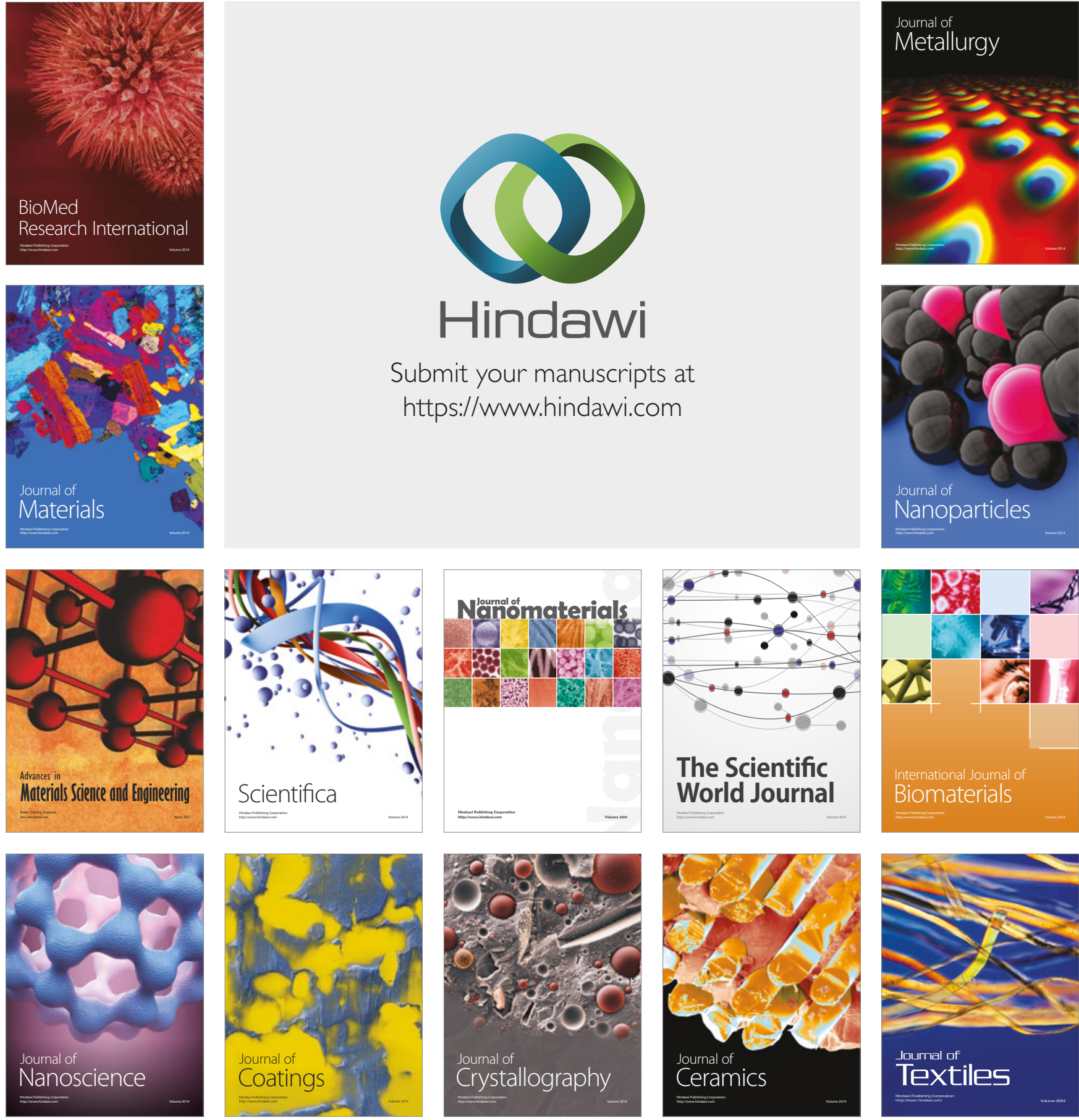

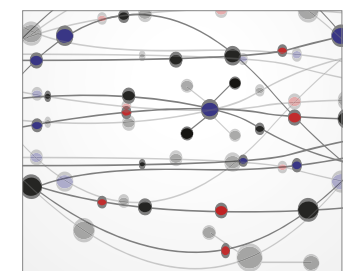

The Scientific World Journal
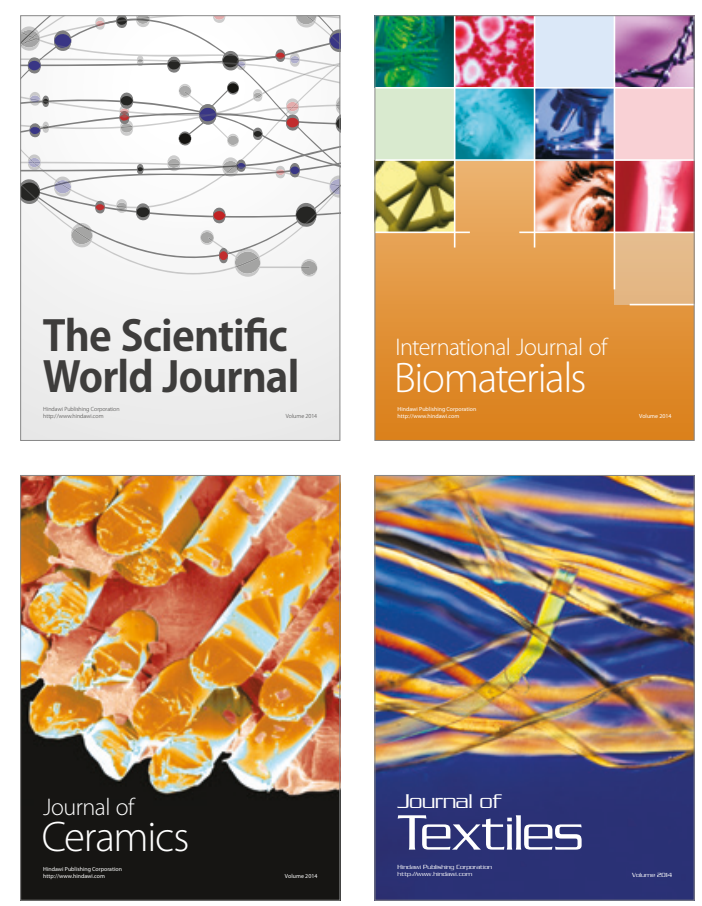